\title{
DIREITO DO TRABALHO E GLOBALIZAÇÃO
}

\section{Lucas Moraes Rau* Marco Antônio César Villatore**}

RESUMO: O presente artigo analisa a conjectura do universo laboral na contemporaneidade. Como o fenômeno denominado de globalização e suas nuances vêm influenciando os trabalhadores e desencadeando uma sociedade de risco. Os impactos culturais, econômicos, políticos e sociais e como estes transformam o trabalho além de influenciar o futuro ocupacional do homem, culminando com o problema do desemprego estrutural, reestruturação do sistema produtivo e da precariedade nas condições de trabalho. A pesquisa, pautada pelo método dedutivo, tem como objetivo analisar parte da bibliografia do assunto para uma compreensão do Direito do Trabalho em um mundo amplamente globalizado.

Palavras-chave: Trabalho Precário, Globalização, Consequências, Flexibilização.

\section{LABOR LAW AND GLOBALIZATION}

\begin{abstract}
The article analyzes the conjecture of the labour world. How the phenomenon called globalization and its nuances has influenced workers and triggering a risk society. The cultural, economical, political and social impacts and how they have transformed labour and influenced occupational future of the man, culminating with the structural unemployment, restructuring of the productive system and precarious working conditions. Finally, bring up perspectives of various scholars of what to expect for the future, demystifying the "myth" of the end of labour. The research is lined by the deductive to understand the Labor Law in a widely globalized world.
\end{abstract}

Keywords: precarious labour, globalization, consequences, flexibilization.

\footnotetext{
* Advogado. Especialista em Direito do Trabalho e Processo do Trabalho pela Universidade Positivo. Mestrando em Direito Econômico e Desenvolvimento pela Pontifícia Universidade Católica (PUCPR). Rua José brenny, 115, Curitiba, Paraná, CEP: 82.120-400, E-mail: lucas231292@ gmail.com

** Advogado. Pós-Doutor em Direito Econômico pela Università degli studi di Roma II, "Tor Vergata". Doutor em Direito do Trabalho e Previdência Social pela Università degli studi di Roma I, "La Sapienza", revalidado pela Universidade Federal de Santa Catarina (UFSC). Mestre em Direito do Trabalho pela PUCSP. Professor Titular do Programa de Pós-graduação (Mestrado e Doutorado) em Direito da Pontifícia Universidade Católica (PUCPR). Professor Adjunto III do Curso de Graduação em Direito da UFSC. Professor do Centro Universitário Internacional UNINTER de Curitiba/PR. Coordenador do Núcleo de Estudos Avançados de Direito do Trabalho e Socioeconômico (NEATES) da PUCPR. Rua Visconde do Rio Branco, 1.341, conjunto 03, Centro, Curitiba, Paraná, CEP: 80.420-210, E-mail: marcovillatore@gmail.com
} 


\section{INTRODUÇÃO}

O labor exerce um papel fundamental na sociedade. Ao longo da história passou a ocupar um papel importantíssimo na realidade das pessoas, trabalho se tornou sinônimo de quem você é. O presente estudo busca esclarecer como esta atividade essencial para nossa subsistência tomou os contornos que conhecemos hoje na globalização.

Esta pesquisa assume importância ao demonstrar que os direitos dos trabalhadores, considerados direitos humanos de segunda geração, são questões de ordem pública e devem ser protegidos.

Justifica-se a relevância do assunto pelo atual fenômeno da globalização e as reconfigurações que vêm acarretando no mundo ocupacional e, por conseguinte, nas garantias fundamentais do trabalhador.

As consecutivas crises capitalistas afetam diretamente as relações laborais. Este estudo busca avaliar o impacto destas crises para a flexibilização e desregulamentação advindas do impacto financeiro nos governos e empresas.

A atual crise mundial, considerada a maior desde a quebra de 1929, trouxe impactos alarmantes para grandes potências. Esta pesquisa busca compreender como estes acontecimentos afetam as relações trabalhistas e a importância de revermos (pre)conceitos para geração e manutenção dos postos de trabalho.

A pesquisa, pautada pelo método dedutivo, tem como objetivo analisar parte da bibliografia do assunto para uma compreensão do Direito do Trabalho em um mundo amplamente globalizado e verificar possíveis causas e soluções para a manutenção dos direitos dos trabalhadores.

\section{INSTITUCIONALIZAÇÃO E CRISE DOS DIREITOS TRABALHISTAS}

Na concepção de Maurício Godinho Delgado, existem três fases históricas do Direito do Trabalho, que atualmente se acrescentaria uma quarta pelo atual contexto de fim do século XX e do início de século XXI. 
A primeira fase é denominada de "Manifestações Incipientes ou Esparsas", em que se buscou reduzir a violência brutal da superexploração empresarial sobre mulheres e menores de 18 anos. $^{1}$

A segunda fase, intitulada “Sistematização e Consolidação", foi marcada pelo Manifesto Comunista. Nas palavras de Delgado, a publicação do Manifesto Comunista em 1848 sepultou a hegemonia no pensamento revolucionário das vertentes insurrecionais ou utópicas.

A terceira fase se chama "Institucionalização" e se inicia em 1919 com o surgimento da OIT e a Constituição de Weimar. Neste momento o Direito do Trabalho passa a ser um ramo jurídico absolutamente assimilado à estrutura e dinâmica institucionalizadas da sociedade civil e do Estado. ${ }^{2}$

Este período coincide com importantes avanços no campo dos direitos humanos. O Tratado de Versalhes criou a Liga das Nações, que posteriormente foi substituída pela ONU que manteve a OIT permaneceu como órgão especializado e comissão permanente. ${ }^{3}$

No pós-Segunda Guerra a economia mundial crescia a uma taxa explosiva. Na década de 1960 era claro que jamais houvera algo assim. Os avanços tecnológicos do período transformaram o capitalismo "a ponto de ficar irreconhecível". 4

Contudo, as crises mostraram novamente sua faceta cíclica. Os tempos de pujança econômica estavam com os dias contados, conforme nos leciona Hobsbawm:

A expansão da economia no início da década de 1970, acelerada por uma inflação em rápida ascensão, maciços aumentos nos meios circulantes do mundo, e pelo vasto déficit americano, tornou-se febril. No jargão dos economistas, o sistema ficou superaquecido. ${ }^{5}$

Em 1971 o colapso financeiro de Bretton Woods, em 1972-3 o boom de produtos e a crise da Organizaçao dos Países Produtores de Petróleo (OPEP) causaram a derrocada política refletida na sociedade. Apesar de alguns avanços, a apatia dos movimentos trabalhistas foi a marca destes anos dourados. Os governos de esquerda, muitas vezes no poder, estavam preocupados apenas em melhorar a condição de vida dos operários com fins eleitorais, ao

${ }^{1}$ DELGADO, Mauricio Godinho. Curso de Direito do Trabalho. 13. ed. São Paulo: LTr, 2014, p. 95.

2 Ibid., p. 98.

${ }^{3}$ Ibid., p. 96.

${ }^{4}$ HOBSBWAM, Eric J. A era dos Extremos. 2. ed. São Paulo: Companhia das Letras, 2013, p. 257.

${ }^{5}$ HOBSBAWM, Op. cit., 2013, p. 280. 
mesmo tempo que observaram calados o avanço tecnológico esvaziar as fábricas e enfraquecer os movimentos sindicais. ${ }^{6}$

Inicia-se assim a quarta fase do Direito do Trabalho na definição de Delgado: a fase de crise e de transição das condições laborativas. Grupos de direita ganham importantes vitórias eleitorais, com consequências de desestruturação do Direito do Trabalho, como as vitórias de Margaret Thatcher, na Inglaterra em 1979; Ronald Reagan, nos EUA, em 1980, Helmut Kohl, na Alemanha, em 1982, e que acabaram com a hegemonia político-cultural de um pensamento desregulatório do Estado de Bem-Estar Social.

No Brasil, a década de 80 foi marcada como a década perdida. A ampliação da dívida externa e o aumento da taxa de juros e a inflação exorbitante devastaram a economia nacional. ${ }^{7}$

No centro dessa diretriz em prol da desregulamentação das políticas sociais e das regras jurídicas limitadoras do mercado econômico se encontrava, por lógica, o Direito do Trabalho.

A crise do Direito do Trabalho se agrava nos anos 1990, com o crescente avanço das novas tecnologias, especialmente na microeletrônica, robotização, microinformática e telecomunicações ${ }^{8}$ deflagraram o fenômeno da globalização; da modernidade reflexiva ou sociedade de risco, termos que serão melhor estudados no decorrer deste trabalho.

Os próprios empregadores passam a se adequar aos novos desafios enfrentados por este processo de mudanças, reduzindo ainda mais os direitos dos trabalhadores. A reestruturação da gestão empresarial, em especial do modelo toyotista, cinde as matrizes tradicionais do Direito do Trabalho.

Encontrar-se o meio termo, como realidade econômica e política, sem polarizações extremistas, não é tarefa nada fácil, em razão dos interesses do capital. Os mercados emergentes ficam a reboque nas grandes economias. Os grandes cedem naquilo que interessa, na falta de um efetivo mecanismo internacional que tivesse o poder de equilibrar a balança de negociações.

Os anos 2000 vêm amargurar novas crises econômicas, em especial a crise do crédito de 2008 que atinge o Brasil com maior intensidade em 2014 ${ }^{9}$, ainda impactando a economia e

\footnotetext{
${ }^{6}$ Ibid., 2013, p. 280.

${ }^{7}$ SINGER, Paul. Globalização e desemprego: Diagnóstico e alternativas. São Paulo: Contexto, 2001, p. 35.

${ }^{8}$ DELGADO, Mauricio Godinho. Capitalismo, Trabalho e Emprego: entre os Paradigmas da Destruição e os Caminhos de Reconstrução. 3. ed. São Paulo: LTr, 2006, p. 36.

9 http://g1.globo.com/economia/noticia/2015/08/brasil-entrou-em-recessao-partir-do-2-trimestre-de-2014-dizfgv.html. Acesso em 20 de junho de 2016.
} 
debilitando ainda mais o quadro empregatício e das garantias laborais. Acerca desta crise, Ricardo Antunes ${ }^{10}$ afirma que presenciamos, ao contrário dos ciclos longos de expansão alternados com crises, "exibe as características de uma crise cumulativa, endêmica, mais ou menos uma crise permanente e crônica (...)", que atinge de forma pungente as relações de trabalho, estimulando reformas precarizantes como alternativas irreais de que os problemas enfrentados são resultado de um sistema laboral muito protetivo.

\section{GLOBALIZAÇÃO}

A globalização pode ser definida como "a intensificação das relações sociais em escala mundial, que ligam localidades distantes de tal maneira que acontecimentos locais são modelados por eventos ocorrendo a muitas milhas de distância e vice-versa". ${ }^{11}$

Mais especificamente para o trabalho, a globalização "é um processo de reorganização da divisão internacional do trabalho, acionado em parte pelas diferenças de produtividade e de custos de produção". ${ }^{12}$

Há entendimento de que a globalização seria uma fase do sistema capitalista ${ }^{13}$, que estruturou seus pilares de produção nesta facilidade de produzir ao menor custo e ampliar seu mercado consumidor graças à conjuntura de fatores políticos, culturais, econômicos e sociais.

Além disso, o sistema globalizado de trabalho está sempre alterando as relções laborais, ora criando novas formas de emprego e em outras extinguindo postos de trabalho, influenciando diretamente as mudanças tratadas a seguir.

\footnotetext{
${ }^{10}$ ANTUNES, Ricardo. Os Sentidos do Trabalho. 2. ed. São Paulo: Boitempo, 2009, Mundo do Trabalho, p. 29.

${ }^{11}$ GIDDENS, Anthony. As consequências da Modernidade. São Paulo: Unesp, 1991. São Paulo: Gen, 2003, p. 76.

12 SINGER, Op. cit., p. 21

${ }^{13}$ DELGADO, 2006, Op. cit., p. 12.
} 


\title{
4 CONSEQUÊNCIAS
}

\subsection{CONSEQUÊNCIAS CULTURAIS}

Culturalmente ocorre a padronização de gostos e de costumes. Segundo Vólia Bomfim Cassar:

\begin{abstract}
Imagens uniformes são replicadas em milhões de telas ao mesmo tempo. A contaminação global por um padrão não é só na música e filmes, mas também no modo de vida, na maneira de vestir e de se comportar. Com isso, esvazia-se a cultura nacional e regional para uma identidade global. Perde-se a identidade, as tradições, as características pessoais. A indústria da propaganda movimenta milhões de dólares ao ano para seduzir e tentar a todos. O tempo está cada vez menor. O ritmo imposto é frenético. Tudo é instantâneo e ao mesmo tempo descartável. ${ }^{14}$
\end{abstract}

Toda esta fugacidade, segundo Baumam ${ }^{15}$, torna uma grande maioria impotente, que observam o local em que habitam se mover sobre seus pés. "A mudança e a rearrumação dos corpos no espaço físico é menos que nunca necessária para reordenar significados e relações."16

A facilidade de acesso a elementos culturais de pontos distantes do globlo eliminam barreiras e preconceitos culturais sem que o indivíduo precise sair de casa, ou ainda implementa em um ambiente diverso um costume que é visto apenas de forma longínqua.

\subsection{CONSEQUÊNCIAS ECONÔMICAS}

No campo econômico, a globalização da economia acarreta a quebra de barreiras entre os países, em que suas fronteiras e limites perdem a importância. Ocorre o que Delgado denomina de generalização do sistema econômico. Esta intensificação das relações comerciais geraram um aprofundamento dos laços entre as nações que resultaram na criação de diversos blocos econômicos, como por exemplo, a União Europeia e o MERCOSUL. Apesar deste

\footnotetext{
14 CASSAR, Volia Bomfim. Princípios Trabalhistas, Novas Profissões, Globalização da Economia e Flexibilização das Normas Trabalhistas. Rio de Janeiro: Impetus, 2010, p. 28

${ }^{15}$ BAUMAN, Zygmunt. Modernidade líquida. Rio de Janeiro: Zahar, 2000, p. 25.

${ }^{16}$ CASSAR, Op. cit., 26.
} 
processo generalizante do capitalismo, "não raras são as vezes em que não ocorre uma efetiva interdependência entre as nações, terminando por acentuar antigas dependências e debilidades". ${ }^{17}$ De um lado se encontram as grandes potências e de outro, a periferia de países.

A extinção das fronteiras aumentou a competitividade, fortaleceu as multinacionais e em muitos casos desestruturou os mercados nacionais, que não conseguiram sobreviver aos estímulos externos, em que o produtor compra a matéria prima em qualquer lugar do mundo, buscando melhores preços, qualidade e condições de pagamento e subsequentemente instala suas fábricas em países cujo custo da mão de obra seja mais barata, enrijecendo a concorrência. $^{18}$

Sob este aspecto, reside um segundo problema enfrentado na modernidade: a ascendência das corporações sob os Estados. Segundo Giddens ${ }^{19}$, "se os Estados-nação são os atores principais dentro da ordem política global, as corporações são os agentes dominantes dentro da economia mundial". A volatilidade do capital, como afirma Baumam, mantém-nas a um passo adiante de qualquer Estado. É a substituição da ideologia de Estado por uma ideologia de Mercado. Discorrendo sobre o tema, Cassar ratifica que os governos se tornam mais vulneráveis à influência das corporações e instituições financeiras globais, que detém o poder econômico.

Em decorrência desta ideologia de mercado, surge uma terceira consequência econômica: a hegemonia do capital financeiro especulativo redirecionando a atuação dos Estados, de modo a garantir a estreita vinculação de suas economias ao mercado globalizado. Se, por um lado, a economia de até duas décadas atrás se centrava no capital produtivo, agora é a especulação financeira quem dita as normas do mercado.

A crise do petróleo e a queda da bolsa de Nova York endividaram externa e internamente as nações, o que gerou um aumento inflacionário e uma acentuação da concorrência interempresarial $^{20}$, que foram responsáveis pela redução dos investimentos sociais, ampliação das crises econômicas e endividamento das regiões periféricas.

${ }^{17}$ CASSAR, Op. cit., p. 15.

${ }^{18}$ SINGER, Op. cit., p. 68.

${ }^{19}$ GIDDENS, Op. cit., p. 83.

${ }^{20}$ ANTUNES, 2009, Op. cit., p. 36. 
Por conseguinte, sempre que há crises o trabalho e os direitos dos trabalhadores sofrem revezes, flexibilizações e precarizações sob a premissa de criação de empregos e modernização das relações trabalhistas.

\subsection{CONSEQUÊNCIAS POLÍTICAS}

No campo político, a partir dos anos 1970 do século passado, fortaleceu-se o neoliberalismo. Frederich von Hayek, um dos seus maiores expoentes, formulou os seguintes princípios norteadores desta política: a) Estado mínimo; b) lei de mercado sobrepondo-se à lei do Estado; submissão do sócioeconômico; d) ataque ao sindicalismo de combate. ${ }^{21}$

Em outras palavras, dá-se preferência às privatizações, quedas de barreiras alfandegárias, livre circulação de bens, serviços e trabalhadores, e desregulamentação de direitos sociais e trabalhistas.

A ausência de um contraponto ideológico, marcadamente enfraquecido pela derrocada soviética, e a atuação concertada das mais importantes agências oficiais nacionais e internacionais de índole econômica, gerando uma combinação cultural uniforme para os meios de comunicação de massa contribuíram ainda mais para este quadro político. Observa-se a partir de então que formalmente "os Estados continuam a exercer suas soberanias, mas no plano real e substancial muitos deles já não têm mais autonomia para estabelecer a política interna desejada, tornando-se incapazes de executar seus objetivos". ${ }^{22}$

Infelizmente, constatamos que este quadro político ainda está em voga no mundo e em nosso país. Principalmente, a partir do governo Fernando Henrique Cardoso, são tomadas medidas de abertura comercial acentuada, desconstrução das políticas industriais, privatizações amplas.

\subsection{CONSEQUÊNCIAS SOCIAIS}

No campo social, enraizou-se a cultura do "eu”. Segundo Ulrich Beck, ocorreu uma transformação social no interior da modernidade, ao longo da qual, as pessoas são libertadas

${ }^{21}$ CASSAR, Op. cit., p. 12.

${ }^{22}$ Ibid., p. 27. 
das formas sociais da sociedade industrial: classe, estrato, família, estatutos de gênero ${ }^{23}$ em um impulso social individualizatório pela fabricação, o autoprojeto e a autorepresentação, não apenas da própria biografia, mas também de seus compromissos e articulações à medida que as fases da vida mudam.

Como bem apontado pelo sociólogo alemão, a individualização da sociedade encontrou forte consentimento no universo do trabalho. Ricardo Antunes ${ }^{24}$, sobre este aspecto, afirma que se presencia um individualismo possessivo, em especial sob o viés empreendedorista, em que até mesmo os trabalhadores perdem a possibilidade de viver da sua força de trabalho.

Depreendemos pelas palavras dos dois sociólogos que as mundanças sociais são as que afetam diretamente a sociedade como um todo. Ela se torna um reflexo do que é decidido no âmbito político e econômico e pelo rápido avanço tecnológico. Neste aspecto, o trabalho, momento fundante da realização do ser social, torna-se "bode expiatório" desta transformação no interior da modernidade. A importância do trabalho, conforme $\operatorname{Marx}^{25}$, é devido ele ser:

[...] uma condição de existência do homem, independentemente de todas as formas de sociedade, eterna necessidade natural de mediação do metabolismo entre homem e natureza e, portanto, vida humana. ${ }^{26}$

No entanto, a partir dos anos 1970, as mutações intensas, econômicas, sociais, políticas e ideológicas, com fortes repercussões no ideário, na subjetividade e nos valores constitutivos da classe-que-vive-do-trabalho estão alterando as relações laborais e os direitos trabalhistas. Se no início do século XX se verificou a universalização de direitos trabalhistas e a constitucionalização de direitos sociais, hoje, com o trespasse do Estado Social para o Neoliberal, o que se vê é um processo de desuniversalização e descontitucionalização de direitos sociais e trabalhistas. ${ }^{27}$

Em razão desta conjuntura de fatos, este estudo provoca os seguintes questionamentos: Quais seriam estas mudanças? Quais são os direitos mínimos do trabalhador? Quais são os mecanismos nacionais e internacionais de tutela do trabalhador? Quais os desafios enfrentados

${ }^{23}$ BECK, Op. cit., p. 107.

${ }^{24}$ ANTUNES, 2012, Op. cit., p. 17.

${ }^{25}$ MARX, Karl. O capital. 3. ed. São Paulo: Abril, 1983, p. 149.

${ }^{26}$ ANTUNES, 2012, Op. cit., p. 17.

${ }^{27}$ DALLEGRAVE NETO, Op. cit., p. 21. 
pelo trabalho e pelo Direito do Trabalho no Estado Neoliberal e na Sociedade de Risco? O que esperar para o futuro?

\section{GLOBALIZAÇÃO E IMPACTO NO UNIVERSO DO TRABALHO}

Como resultado desta conjuntura socioeconômica, se pode elencar três reflexos sensíveis nas relações de trabalho: a) aumento do desemprego mundial, antes pontual, agora estrutural; b) reestruturação do sistema produtivo; c) precariedade nas condições de trabalho. ${ }^{28}$

Os três reflexos demonstram como os direitos dos trabalhadores são afetados, infelizmente quase sempre de forma negativa, retirando direitos.

\subsection{DESEMPREGO ESTRUTURAL}

O desemprego, a partir de meados dos anos 1970, tornou-se, de modo notório, fenômeno socieconômico persistente e grave. Ao invés da natureza conjuntural, normalmente resultado de uma crise, o desemprego a partir daí assume caráter estrutural. Segundo Delgado, a terceira revolução tecnológica, o processo de reestruturação capitalista e a acentuação da concorrência capitalista são os fomentadores desta mudança.

O primeiro destes fatores envolve significativas inovações e aperfeiçoamentos no campo da tecnologia, que afetam de modo direto o processo de realização do trabalho.

O desemprego é um dos problemas mais sérios da atualidade. Segundo o relatório da OIT, no ano de 2013, o mundo atingiu a marca de 202 milhões de desempregados, o que representa 6\% em nível mundial. As previsões são de que em 4 anos, 215 milhões de pessoas estejam desempregadas. ${ }^{29}$

Esta alta taxa de desemprego levanta uma análise interessante, elaborada por Jorge Luiz Souto Maior ${ }^{30}$. Ele afirma que o "pleno emprego, que fora uma promessa do Estado Social, com força jurídica dentro do sistema, passa a ser, abertamente, apontado como sonho

\footnotetext{
${ }^{28}$ DALLEGRAVE NETO, Op. cit., p. 29.

${ }^{29}$ Desemprego mundial atingiu mais de 200 milhões de pessoas em 2013, aponta relatório da OIT. Revista Fórum. Disponível em: http://www.brasildefato.com.br/node/27140. Acesso em 5 de junho de 2017.

${ }^{30}$ SOUTO MAIOR, Jorge Luiz. O Direito do Trabalho como instrumento de Justiça Social. 4. ed. São Paulo: LTr, 2000, p. 85.
} 
inatingível". Ele se utiliza deste argumento para demonstrar que se chega ao "cúmulo de se dizer que a desgraça daqueles que não têm emprego é culpa dos empregados, em razão dos direitos que possuem". Quando na verdade, a culpa está no aspecto estrutural da economia. ${ }^{31} \mathrm{O}$ próprio relatório da OIT sustenta que as perspectivas negativas de emprego a longo prazo estão relacionadas "à falta de investimentos na economia real, pois o lucro obtido em vários setores é destinado, principalmente, aos mercados de ativos". ${ }^{32}$

Portanto, é latente que apesar de todas as justificativas, os interesses dos investidores e grandes empresários são os maiores beneficiados com as mudanças globalizadas dos tempos de crise, com a redução dos direitos trabalhistas e consequente aumento de poder perante o trabalhador.

\subsection{REESTRUTURAÇÃO DO SISTEMA PRODUTIVO}

O segundo fator envolve significativas modificações econômicas e organizacionais no plano da estruturação das empresas, ou seja, mudanças que se verificam no próprio processo de organização das entidades empresarias e nos sistemas de produção internos a estas entidades. ${ }^{i}$

Até meados de 1970, o sistema de gestão empresarial prevalescente era conhecido por fordismo/taylorismo ${ }^{33}$. Este modelo propunha uma uma especialização das tarefas e rotinização do processo produtivo, transformandoa em uma sequência de atos simples repetidos durante toda a jornada daquele trabalhador.

No entanto, a crise estrutural do capitalismo ${ }^{34}$ fez com que fosse implementado um amplo processo de reestruturação com vistas à recuperação do seu ciclo reprodutivo, o que culminou com o toyotismo/ohnismo, que busca o conceito de empresa enxuta, elevando a

\footnotetext{
${ }^{31}$ CASSAR, Op. cit., p. 14. "O desemprego, no Brasil, ocorre em virtude de uma política econômica interna recessiva (juros altos), baixos valores das aposentadorias que acabam incentivando a permanência do aposentado no mercado de trabalho; início precoce do trabalho infantil para aproveitamento na renda familiar; falta de investimento interno em políticas públicas, de modo a incentivar a criação e manutenção de pequenas e médias sociedades empresárias."

${ }^{32}$ SOUTO MAIOR, Op. cit., p. 85.

${ }^{33}$ DELGADO, 2006, Op. cit., p. 41.

34 ANTUNES, 2009, Op. cit., p. 37. "O entendimento dos elementos constitutivos essenciais dessa crise é de grande complexidade, uma vez que nesse mesmo período ocorreram mutações intensas, econômicas políticas, ideológicas, com fortes repercussões no ideário, na subjetividade e nos valores constitutivos da classe-que-vivedo-trabalho".
} 
produtividade e o foco na subcontratação de empresas, focando em si as atividades essenciaisa seu objeto principal.

Esta subcontratação empresarial, mais conhecida como terceirização, é a razão de grande desregulamentação dos direitos trabalhistas. Segundo Souto Maior a terceirização acaba provocando uma pulverização da massa trabalhadora, o que inibe a luta por melhores condições de trabalho, dificultada pela névoa que repousa sobre as relações empregatícias que no trabalho terceirizado dificultam a identificação do real empregador. ${ }^{35}$

Do mesmo modo, enfraquece-se o movimento sindical, uma vez que os tercerizados fazem parte do setor terciário, fracionando a atuação dos sindicatos.

Outro fator desestruturante é que embora não reduza necessariamente postos de trabalho, em um primeiro momento, ela reduz os custos empresariais) diminuindo o "custo da empresa-pólo, o incremento da produtividade do trabalho, por ser, de maneira geral, muito mais modesto o padrão de pactuação trabalhista". ${ }^{36}$

Este é um movimento sem volta, as empresas cada vez mais globalizadas espalham-se pelo globo em busca de melhores oportunidades, mão de obra barata e qualificada.

\subsection{PRECARIEDADE NAS CONDIÇÕES DE TRABALHO}

As crises estruturais e econômica do capitalismo e o pensamento predominantemente neoliberal incrementaram o novo proletariado, do subproletariado fabril e de serviços, o que tem sido denominado mundialmente de trabalho precarizado.

As últimas medidas legislativas de âmbito nacional e interncional demonstram a flexibilização das relações de trabalho, em especial no que se refere "aos critérios de admissão, pagamento de salário, compensação de jornada e ainda os de alteração, suspensão e rescisão do contrato de trabalho". ${ }^{37}$

Por flexibilização, que não pode ser considerada o mesmo que desregulamentação, depreende-se que seja:

\footnotetext{
${ }^{35}$ SOUTO MAIOR, Op. cit., p. 320.

${ }^{36}$ DELGADO, 2006, Op. cit., p. 38.

${ }^{37}$ DALLEGRAVE NETO, Op. cit., p. 33.
} 
[...] a adaptação das regras trabalhistas à nova realidade das relações de trabalho, que permite, e muitas vezes exige, um reordenamento do sistema jurídico, não necessariamente no sentido de diminuição de direitos ou de exclusão de regras positivadas, mas no sentido de regular, de modo diferente, as relações de trabalho. ${ }^{38}$

"A corrente doutrinária desenhada por juristas do novo paradigma neoliberal patrocinada por empresários e organizações financeiras mundiais" defende a solução negociada e detrimento da solução legislada. Para eles as negociações coletivas impõem uma regulação cogente não adaptável às diferentes e mutáveis hipóteses ocorrentes no mundo da produção. ${ }^{39}$

Afirmam também que "os direitos trabalhistas e socias são vistos sob uma ótica estritamente econômica, significando" encargo social, custo, passivo trabalhista e um estorvo para a maior lucratividade da empresa". ${ }^{40}$

No Brasil, a atual reforma trabalhista, materializada com o Projeto de Lei n ${ }^{\circ} 13467 / 2017$ dispõe que o acordado prevalesce sobre o legislado desde que respeite à Constituição.

A nova legislação um limbo jurídico em nosso país. Na crítica feita por Luiz Salvador, este tipo de reforma cria um verdadeiro retrocesso social no país, prevalescendo a Barbárie ao invés do Direito. A fragilidade das entidades sindicais na atual conjuntura de recessão e desemprego afasta qualquer pressuposto de igualdade. A igualdade deve ser fática, e não ficta.

Este processo de precarização das condições laborais gerou também o fenômeno da desregulamentação. Ele confere a "eliminação de diversas regras estatais trabalhistas, buscando uma regulamentação por ação dos próprios interessados" ${ }^{41}$. Cassar reitera que enquanto na flexibilização se ameniza os efeitos rígidos da lei, permitindo exceções em casos especiais, na desregulamentação se caracteriza total ausência do Estado (da lei) disciplinando as condições mínimas de trabalho. ${ }^{42}$

Como causa direta da desregulamentação, ocorre o aumento da informalidade. Segundo dados da Organização Para Cooperação e Desenvolvimento Econômico (OCDE), existem, atualmente (2010) no mundo, 1.8 bilhão de trabalhadores no setor informal, ou seja, $60 \%$ da

\footnotetext{
38 SOUTO MAIOR, Op. cit., p. 139.

${ }^{39}$ ROMITA, Arion Sayão. Flexisegurança: a reforma do Mercado de Trabalho. São Paulo: LTr, 2008 , p .31.

${ }^{40}$ DALLEGRAVE NETO, Op. cit., p. 30.

${ }^{41}$ SOUTO MAIOR, Op. cit., p. 139.

${ }^{42}$ CASSAR, Op. cit., p. 42.
} 
força de trabalho global trabalham sem vínculo de emprego, enquanto 1.2 bilhão com contrato de trabalho formalizado.

A flexibilização, ao menos na teoria, era para se direfenciar da desregulamentação pela garantia do Estado de direitos básicos, um núcleo de normas de ordem pública permanente intangível, "pois sem estas não se pode conceber à vida do trabalhador com dignidade, sendo fundamental à manutenção do Estado Social". ${ }^{43}$

Apesar disso, infelizmente, na prática tem sido adotada como forma de reduzir direitos dos trabalhadores, quebrando a rigidez da legislação trabalhista para diminuir os desembolsos com pessoal.

No caso brasileiro, a flexibilização extinguiu a estabilidade absoluta do emprego ao permitir o empregador despedir sem justa causa o empregado; criou-se a suspensão do contrato com incentivo tributário; gerou um rol de modalidades de contratações que prejudicam o trabalhador (trabalho por duração limitada, sem aviso prévio de FGTS; através de relações civis: cooperativas; estágios, representantes comerciais, trabalho voluntário) e, permitiu alterações contratuais sem ônus (reversão de cargo de confiança, opção para trabalho a tempo parcial, redução de salário mediante negociação coletiva; flexibilização da jornada de trabalho de forma unilateral pelo empregador num amplo prazo de um ano através de banco de horas).

Este rol só comprova que a 'suposta rigidez' da legislação trabalhista é apenas retórica, resultado de um discurso mitificado, usado repetidamente pela mídia, o que fez ser admitido como verdadeiro por muitos, mesmo sem um efetivo apontamento específico de fundamentos que lhe dessem respaldo.

O próprio discurso de que a CLT é antiga e que portanto não traduz as novas condições de trabalho se torna uma falácia, uma vez que a CLT é constantemente alterada pelo Tribunal Superior do Trabalho através de súmulas e de orientações jurisprudenciais.

\footnotetext{
${ }^{43}$ DALLEGRAVE NETO, Op. cit.., p. 30.
} 


\title{
6 O MITO DO FIM DO TRABALHO
}

O "mito" de que estamos na era sem trabalho foi propugnada pela primeira vez pelo economista americano Jeremy Rifkin. Este diagnóstico negativo, no entanto, mostra-se infundado:

\begin{abstract}
O emprego não acabou e não vai acabar, pelo menos enquanto se mantiver em vigor o sistema de produção capitalista. Este sistema econômico tem como fundamento de sua própria existência a acumulação de um capital que permite a seu possuidor, o capitalista, utilizar, a força de trabalho livre, dita "assalariada", para incremento de uma atividade que lhe permita adicionar mais capital (obter lucro), exatamente pela utilização do trabalho alheio. ${ }^{44}$
\end{abstract}

Ricardo Antunes é do mesmo pensamento. Segundo ele o mundo produtivo e de serviços ainda carece de uma dada forma de trabalho, seja ele material, produtivo ou imaterial. O trabalho, portanto, não se tornou mera virtualidade, ainda que venha sofrendo mutações e metamorfoses significativas. $^{45}$

Nesta nova dinâmica, muito influenciada pelos fatores que, são as causas atuais desta crise estrutural da economia e do trabalho, é que se vaticinou o fim dos empregos. No entanto, conforme já exposto, o "capital pode reduzir muito, mas não pode eliminar completamente o trabalho vivo do processo de criação de mercadorias". ${ }^{46}$ O que acontece é a intensificação da exploracão do trabalho (flexiblização, terceirização, regime parcial), redução do trabalho fabril e ampliação do trabalho intelectual.

Apesar das novas profissões que surgem com a tecnologia, o mercado não é capaz de suprir a demanda da classe trabalhadora. Torna-se cada vez mais imprescindível que o profissional seja "qualificado, participativo, multifuncional, polivalente e dotado de maior realização no espaço de trabalho". ${ }^{47}$

Em meio a tantas incertezas, Beck acredita que esse sistema de desemprego foi integrado ao sistema empregatício". Ele acredita que estas novas formas de subemprego que surgiram

45 ANTUNES, 2009, Op. cit.., p. 46.

${ }^{46}$ SOUTO MAIOR, Op. cit., p. 22.

${ }^{47}$ Ibid, p. 22. 
"implicam mais trabalho assalariado do que nunca". Tudo "aquilo que até o momento foi consideradio antiético - trabalho formal e informal, emprego e desemprego- será no futuro amalgamado num novo sistema de formas flexíveis, plurais e precárias de subemprego [...] típico da sociedade de risco". ${ }^{48}$

Ele também aponta algumas alternativas, integrando o ócio com o trabalho: elevação da idade mínima com que se obtém o primeiro emprego; redução da idade média com que se aposentar; criação de empregos de meio período; redução do tempo mínimo para a aposentadoria e da duração semanal; aumento da duração média de férias coletivas, dispensas e licenças; elevação da frequência de interrupções do trabalho em razão da participação em cursos de educação continuada ao longo de toda carreira profissional, etc.

Segundo Dallegrave Neto, “a redução da jornada de trabalho, política pública de geração de emprego; incentivo fiscal às microempresas, as quais proporcionalmente, empregam mais que as grandes empresas", são saídas para o desemprego. ${ }^{49}$

As Cooperativas também podem ser uma saída para enfrentar o atual desemprego. Por meio delas cria-se as condições necessárias para que ex-desempregados tenham um Mercado protegido da competição externa, uma vez que estimula o consume interno dos seus produtos por meio de um crédito solidário. ${ }^{50}$

Outrossim, torna-se interessante a solução que países como Dinamarca, França e Espanha têm apresentado e que se chama flexisegurança. Ela consiste na combinação de flexibilidade e segurança, "baseada na observação de que a globalização e o progresso tecnológico acarretam uma rápida evolução das necessidades dos trabalhadores e das empresas". ${ }^{51}$ Em outros termos, define-se uma estratégia política em que se alia a nova flexibilidade do mercado de trabalho a segurança do emprego. Deixa-se de lado a noção de segurança no emprego, para a segurança da empregabilidade. Dá-se maior proteção às pessoas do que aos empregos. Para isto, deve-se priorizar a aprendizagem e uma formação para toda a vida, prezando pela igualdade de oportunidades e de gênero. ${ }^{52}$

A articulação de uma nova ordem social não pode prescindir da educação para dar condições ao próprio trabalhador de fazer escolhas, especialmente no que diz respeito à

\footnotetext{
${ }^{48}$ BECK, Op. cit.., p. 35.

${ }^{49}$ DALLEGRAVE NETO, Op. cit., p. 30.

${ }^{50}$ SINGER, Op. cit., p. 124.

${ }^{51}$ ROMITA, 2008, Op. cit., p. 81.

${ }^{52}$ Ibid., 2008, p. 81.
} 
implantação de políticas públicas que viabilizem efetiva inclusão social, buscando diminuir a miséria social. Toda miséria que impera dentro do sistema capitalista indica que ele não trouxe o progresso que seria esperado.

Enfim, a história do Direito do Trabalho não pode ser esquecida. A criação de formas alternativas de exploração do capitalismo não deve afastar o Direito do Trabalho, que nasceu e cresceu sobre esta lógica ${ }^{\mathrm{ii}}$, de proteção e amparo aos hipossuficientes das relações de trabalho, e ainda, de adequação frente as mudanças contínuas sociais, políticas e econômicas.

\section{CONCLUSÃO}

A história do trabalho como conhecemos hoje se iniciou na Revolução Industrial. O desenvolvimento tecnológico visto naquela época propiciou melhores condições laborais e fortaleceu os movimentos que lutavam pelo fim da exploração sem medida que os operários eram subjugados.

A partir do século XX com a criação da ONU e da OIT e, em âmbito nacional, com a Consolidação das Leis do Trabalho e o surgimento da Justiça do Trabalho e do Ministério Público do Trabalho, o Direito Laboral começa a ser delineado, não apenas como forma de conter abusos, mas de garantir direitos.

Consequentemente a isto, o capitalismo do fim do século XX e início deste século XXI, e sua lógica do risco, apresentam novos desafios à garantia do emprego e aos direitos já alcançados. Se antes a tecnologia foi muito útil aos empregados, temos hoje o desafio frente à desregulamentação e extinção de postos de trabalho.

O Direito Laboral é verdadeira ferramenta como forma de proteção e ampliação dos direitos da classe trabalhadora e de manutenção do próprio sistema. Não se trata, portanto, o direito do trabalho, meramente de quantificação econômica do trabalho no contexto da produção capitalista. Trata-se de um fenômeno jurídico que envolve aspectos socais, macroeconômicos e políticos extremamente relevantes. O Direito do Trabalho, base dos direitos sociais representa imposição de limites necessários ao capitalismo.

Logo, esta premissa de que o emprego irá acabar, fornece ao modelo capitalista a fómula para se desenvolver sem o antagonismo da classe trabalhadora. O Direito do Trabalho deve ser instrumento para a construção de uma sociedade mais justa, mesmo que forças econômicas 
afastem leis sociais, ou influenciando a política, façam criar leis antissociais, pois o direito é algo que está acima da lei.

Em um contexto societal, em que os valores de uso, que correspondem à necessidade do produto, são subordinados aos valores de troca, configurando uma lógica de mercado e não de produção de coisas socialmente úteis, o Direito Laboral se torna imprescindível.

Como instrumento de regulação social do trabalho, base de subsistência da conduta individualizada dos indivíduos, o Direito do Trabalho deve rememorar as razões históricas de seu surgimento e manter este papel protetivo e ampliativo de direitos frente aos novos riscos sociais, culturais econômicos e políticos que o desafiam ininterruptamente.

\section{REFERÊNCIAS BIBLIOGRÁFICAS}

ANTUNES, Ricardo. Os Sentidos do Trabalho. 2. ed. São Paulo: Boitempo, 2009, Mundo do Trabalho.

O caracol e sua Conha: Ensaios sobre a nova morfologia do trabalho. 3. ed. São Paulo, 2012, Mundo do Trabalho.

BAUMAN, Zygmunt. Modernidade líquida. Rio de Janeiro: Zahar, 2000.

Globalização: as consequências humanas. Rio de Janeiro: Zahar, 1999.

BECK, Ulrich. Sociedade de risco. São Paulo: 34, 2010.

CASSAR, Volia Bomfim. Princípios Trabalhistas, Novas Profissões, Globalização da Economia e Flexibilização das Normas Trabalhistas. Rio de Janeiro: Impetus, 2010.

DALLEGRAVE NETO, José Affonso. Inovações na Legislação trabalhista. São Paulo: LTr, 2002.

DELGADO, Mauricio Godinho. Curso de Direito do Trabalho. 13. ed. São Paulo: LTr, 2014.

Capitalismo, Trabalho e Emprego: Entre os Paradigmas da Destruição e os

Caminhos de Reconstrução. 3. ed. São Paulo: LTr, 2006.

Rev. de Direito e Sustentabilidade | e-ISSN: 2525-9687 | Maranhão | v. 3 | n. 2 | p. 90 - 108 | Jul/Dez. 2017. 
GIDDENS, Anthony. As consequências da Modernidade. São Paulo: Unesp, 1991. São Paulo: Gen, 2003.

HOBSBAWM, Eric J. A Era dos Extremos. 2. ed. São Paulo: Companhia das Letras, 2013.

A Era das Revoluções. 25. ed. São Paulo: Paz e Terra, 2010.

MARX, Karl. O capital. 3. ed. São Paulo: Abril, 1983.

ROMITA, Arion Sayão. Flexisegurança: A reforma do Mercado de Trabalho. São Paulo: LTr, 2008.

SINGER, Paul. Globalização e desemprego: Diagnóstico e alternativas. São Paulo: Contexto, 2001.

SOUTO MAIOR, Jorge Luiz. O Direito do Trabalho como instrumento de Justiça Social. 4. ed. São Paulo: LTr, 2000. 